\title{
Epidemiology and patterns of lower limb injuries at a tertiary care hospital in Ahmedabad
}

\author{
Goel SA ${ }^{1}$, Bhavsar NM², Makwana $\mathbf{H}^{3}$, Lil NA ${ }^{4}$, Patel $\mathbf{P R}^{5}$
}

${ }^{1}$ Dr. Shakti A.Goel, Post graduate student, Department of Orthopedics, ${ }^{2}$ Dr. Neel M. Bhavsar Assistant Professor, Department of Orthopedics, ${ }^{3}$ Dr. Harsha Makwana, Associate Professor, Emergency Medicine department, ${ }^{4}$ Dr. Nadeem A. Lil, Associate Professor Department of Orthopedics, ${ }^{5}$ Dr. Pankaj R. Patel, Professor, Department of Orthopedics and Dean, Vadilal Sarabhai General Hospital and Smt. NHL Municipal Medical College, Ahmedabad, Gujrat, India

Address for Correspondence : Dr. Nadeem A. Lil, Associate Professor, Department of Orthopaedic Surgery, Smt. NHL Municipal Medical College, Seth Vadilal Sarabhai General Hospital, Ahmedabad, Gujarat, India., Email: nadeemlil@yahoo.com

\begin{abstract}
Introduction: In the recent era of trauma, about one million people get seriously injured annually. Majority of them suffer from lower limb injuries. Due to lack of trauma registry in India, prediction models are not much effective. The aim of our study was to derive basic epidemiological parameters for lower limb injuries which can be used to develop better prediction models to reduce morbidities and mortalities. Methods: We conducted an observational study on isolated lower limb injuries without any musculoskeletal disorder at a tertiary care institution in Ahmedabad between January 2013 \& October 2014. The lower limb injuries were classified as per the Limb Salvage Index score (LSI) for further management. Results: A total of 1160 patients were included. Mean age was 44.5 years and 75 percent of them were males. Lower limb injuries showed bi-modal age group with first peak between 30 to 40 years and second at 60 to 70 years. Road traffic accidents were the most common cause of injury followed by fall at home. 1.8 percent patients had Limb Salvage Index ranging between 7 to 12 and underwent amputations. Both lower limbs were almost equally affected with left showing a little higher value than right (49 versus 47 percent, $p>0.05$ ). Femur was the most commonly affected bone. Conclusion: This study helped us in identifying certain characteristics that may be useful for planning preventive strategies in an attempt to reduce the numbers of accidents and redirect public investment in health.
\end{abstract}

Keywords: Ahmadabad, Epidemiology, Limbs, LSI, Trauma

\section{Introduction}

Gujarat is one of the fastest developing state in India. With the advent of new technology, architecture and modes of transportation, the pattern of trauma has changed dramatically. According to the recent WHO report, trauma would be the third largest killer in developing countries by 2020 [1,2] . Currently there are two major tertiary care public hospitals in Ahmedabad which are catered by the emergency 108 services. Vadilal Sarabhai General Hospital is one of them. The patients brought to this hospital are from a radius of more than 120 Kilometers. In this study we have analyzed the lower limb injuries at Vadilal Sarabhai General Hospital, Ahmedabad, during a period from January 2013 to October 2014 and determined their

Manuscript received: $26^{\text {th }}$ Apr 2015

Reviewed: $4^{\text {th }}$ May 2015

Author Corrected: $14^{\text {th }}$ May 2015

Accepted for Publication: $6^{\mathrm{t}}$ June 2015 epidemiology and initial outcomes.

Worldwide about 3000 people die every day and 30,000 are injured seriously in traffic accidents . Costs are high when considering developing countries where the vulnerable traffic users are pedestrians, cyclists and motorcycles. Developing countries like India have a DALY score and a major contribution to this is made by trauma which affects both ; quality of life (QOL) and the years of life lost (YLL).

Trauma accounts for about 12 percent of all causes of death worldwide. Being a significant cause for the lower limb amputations in population less than 50 years ; it affects the individual and the society. Getting back into life after amputation comes with many problems. Due to failure to comply with new conditions these 
people may suffer from psycho-social difficulties like depression, sense of hopelessness, low self esteem, boredom, anxiety, frustration, fear of family future, which sometimes leads them to commit suicide. In developing countries like India, a majority of such injuries occurs in the poor strata of the society. Many of them are labourers, commercial workers and people living on daily wages. The natural limb is desired by them to maintain livelihood by performing their activities. Unlike western countries, where majority of health conditions are catered by insurance, these individuals neither have insurance nor means to purchase high cost prosthesis. This leads them to purchase low quality prosthesis which not only limits their activity but also causes complications like pressure sores.

Trauma epidemiology is essential to describe the morbidity, disability and dependency as well as defining the most important target for prevention regarding the severity of injury. The prevention of lower limb injuries is more important for developing nations like India for its economy. It has been previously shown that lower limb injuries constitute the majority in trauma and road traffic accidents [3]. Lower limb injury generally involves young and productive people so it is the prime responsibility of the society to prevent such incidents [4-7].

Hence we decided to study the epidemiology and pattern of lower limb injury at our hospital. We have studied 1160 cases of lower limb injuries requiring admission for orthopaedic intervention and management. Patients with isolated lower limb injuries without any previous musculo skeletal disorder were included in our study. The data was collected in regard to age, sex, mode of injury, time of injury, part of limb involved and initial outcomes. Very few studies have been published on this so ours will highlight insight to lots of epidemiologist, emergency physicians, orthopaedic surgeons and further aid its preventive measures.

\section{Materials and Methods}

In this observational study the patients with lower limb injuries reporting to emergency department of our hospital from a period of January 2013 to October 2014 included were selected.

The patients had reported to the hospital in the months of January 2013 to October 2014. The group was studied for lower limb injuries caused by road traffic accidents, fall from height, fall at home, farm accidents and sports injuries. Data survey included age, gender, location and type of trauma, injury mechanism, anatomical site of injury, initial outcomes and complications.

The isolated lower limb injuries were analyzed as per the Limb Salvage Index (LSI) as suggested by Russel et al [8]. Injured lower limbs were classified according to the score from 0 to 14 and appropriate management was taken.

\section{Protocol for initial management}

The initial management of patients with lower limb injuries varied with the type of trauma encountered. All patients underwent airway breathing and circulation assessment and those with open grade fractures and blood loss were given fast intra venous fluids to control further blood loss.
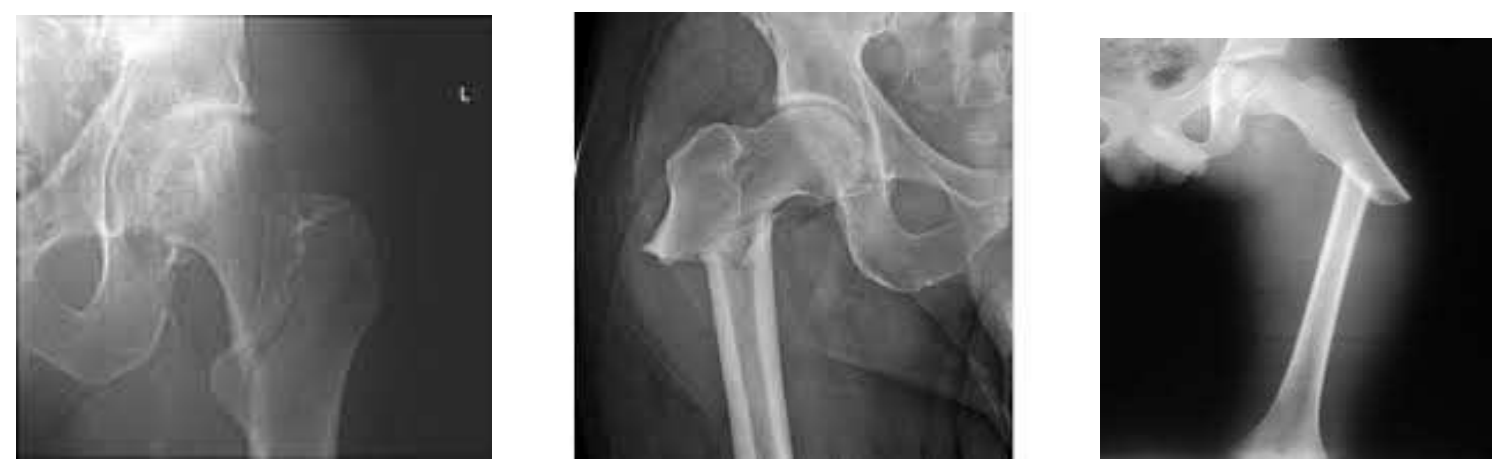

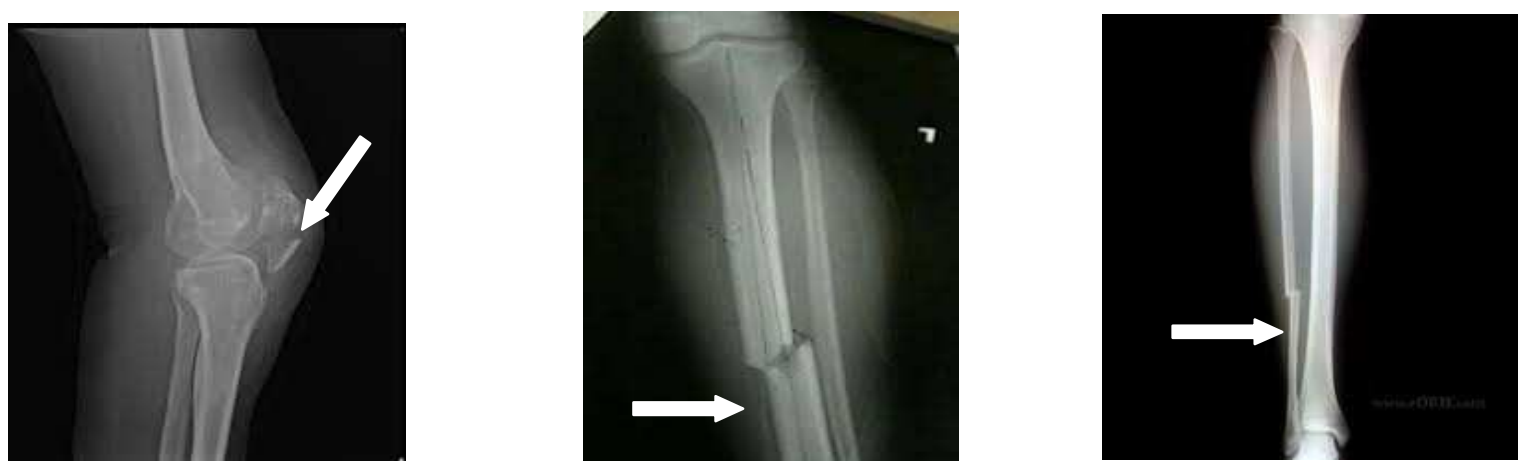

Fig 1 \& 2: Inter-trochanteric Femur Fracture, Subtrochanteric Femur Fracture, Shaft Femur Fracture, Patella Fracture, Shaft Tibia fracture, Isolated Fibula Fracture

Intertrochanteric and Subtrochanteric Femur fractures were managed primarily by anklet skin traction and then $\mathrm{X}$ rays of the limb were conducted (Figure 1,2).

Patients with shaft femur fractures were monitored vitally for shock management due to frequent severe blood loss in such injury. Two wide bore intra-venous cannulas were inserted and fluids and blood were started almost immediately and Bohler splint with anklet traction were given before taking X -rays (Supplemental Figure 2). Patients in severe shock or having complications like fat embolism requiring long term medical care, were managed with upper Tibial Steinman pin traction with one brick and Bohler elevation.
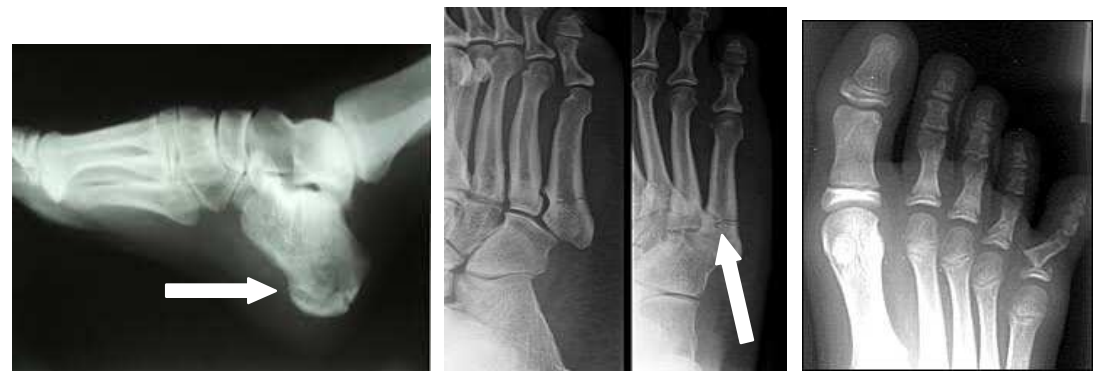

Fig 3: Calcaneal fracture, fracture of fifth metatarsal, Fracture of $5^{\text {th }}$ toe proximal phalynx

Displaced patellar fractures were managed primarily by aspiration of blood from the knee and RJ bandage with AK-BK (Above Knee and Below Knee) slab and elevation ( Supplemental Figure 2). AK (Above Knee) slabs were applied to closed shaft tibial fractures with Bohler elevation (Supplemental figure 2). Patients, in which operative intervention was not possible immediately, were managed with Calcaneal Steinman pin traction (Supplemental Figure 2). Tarsal, metatarsal and phalyngeal fractures were managed with below knee (BK) slabs and BK slabs with toe rests respectively.

\section{Results}

Data were collected between January 2013 to October 2014, showing total of 1160 patients ,who were victims of isolated lower limb injuries due to trauma. The mean age of patients was 44.5 years (minimum 5 years and maximum 95 years) with majority being males (Figure 4(A) and (B)). 


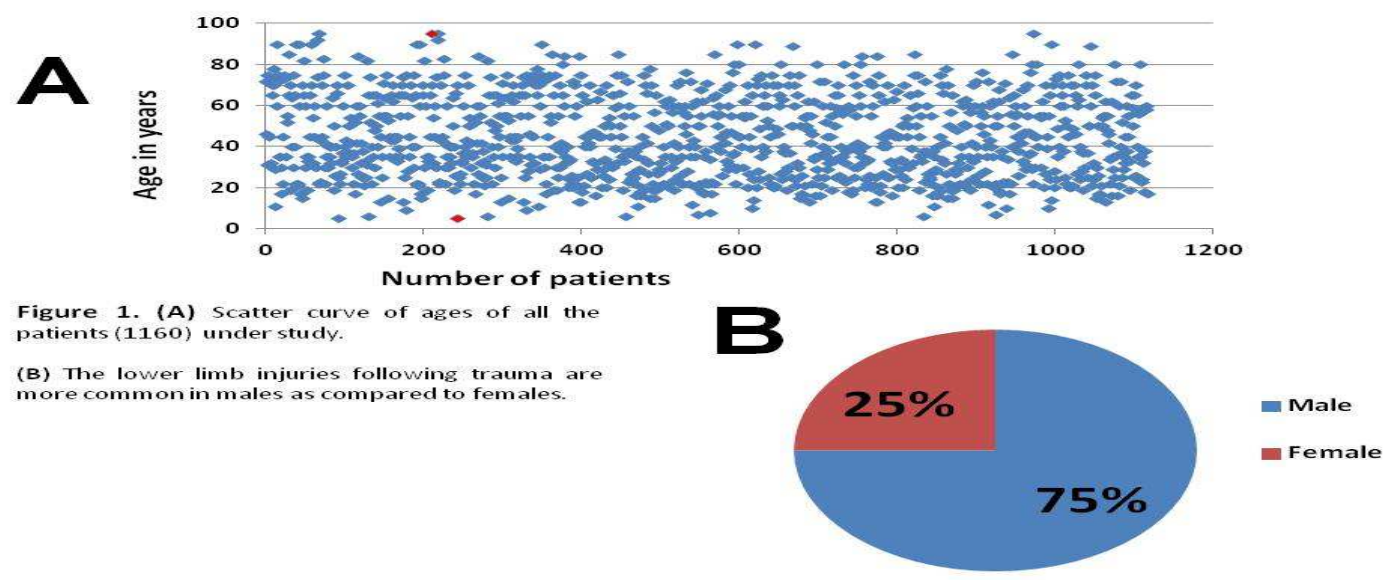

Figure 4.(A) Scatter curve of the ages of all the patients under study (1160). (B) The lower limb injuries are more common in males as compared to females.

The distribution of isolated lower limb injuries showed bimodal curves, one at 20-40 years and another at 61 to 70 years of age(Table 1). The majority of young population had fractures of shafts of long bones while inter-trochanteric and neck femur fractures were common in elderly population (Figure 5 ). A major proportion of this trauma occurred due to road traffic accidents as compared to other modes of injury (2.12:1) (Table 2). One of the reasons for such an observation may be the location of our hospital near a national highway. Fall from height, sports injuries and farm accidents were minor contributing events for the same.

Table 1: Distribution of lower limb injuries

\begin{tabular}{|l|l|}
\hline Age (Years) & Number of patients \\
\hline$<10$ & 14 \\
\hline $11-20$ & 75 \\
\hline $21-30$ & 190 \\
\hline $31-40$ & 253 \\
\hline $41-50$ & 139 \\
\hline $51-60$ & 135 \\
\hline $61-70$ & 177 \\
\hline $71-80$ & 107 \\
\hline $81-90$ & 51 \\
\hline $91-100$ & 19 \\
\hline
\end{tabular}

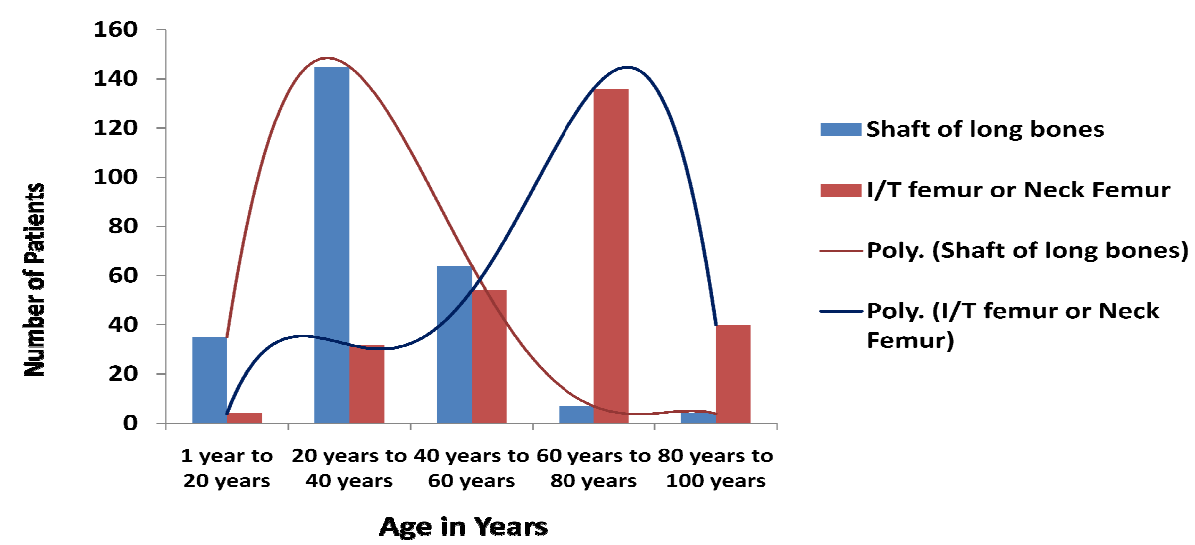


Figure 5: Age wise distribution of fractures of shaft of long bones versus inter-trochanteric and neck femur fractures in random population suffering with traumatic lower limb injuries. Polynomial lines show difference in fracture pattern with age.

Table 2: Mode of injury in patients with lower limb trauma

\begin{tabular}{|l|l|}
\hline Mode of Injury & Percentage of Population \\
\hline Road Traffic Accidents & 72 \\
\hline Fall from Height & 6 \\
\hline Fall at Home & 16 \\
\hline Sports Injury & 2 \\
\hline Farm Accidents & 4 \\
\hline
\end{tabular}

Road traffic accident is the cause in majority of the cases followed by fall at home.

The isolated lower limb injuries were classified as per the Limb Salvage Index (LSI) [8]. Out of 1160 patients we observed, about 51 (4.4\%) had Distal Neuro Vascular Damage and a LSI ranging from 4 to 12. About 20 of them (4.4\%) had LSI score 7 to 12 and underwent amputations.

There was little variation between the limb involved. Our study showed that left lower limbs (49\%) were slightly more affected than the right ones (47\%, p>0.05). About 4 percent of our patients with isolated lower limb injuries showed bilateral lower limbs involvement. However, the pattern of fracture and bones involved varied in the both lower limbs.

Table 3: Lower limb structures involved in isolated injuries. Femur constitues the majority followed by Tibia

\begin{tabular}{|l|l|}
\hline Structures involved & Percentage \\
\hline Acetabulum & 3 \\
\hline Femur & 44 \\
\hline Tibia & 36 \\
\hline Fibula & 3 \\
\hline Patella & 3 \\
\hline Minisci & 6 \\
\hline Tarsal & 2 \\
\hline Metatarsal and Phalynges & 3 \\
\hline
\end{tabular}

Majority of the fractures due to lower limb injuries involved long bones like Femur (43\%), Tibia (35\%) and remaining were acetabular injuries (3\%), patellar fractures, miniscal injuries and fractures of tarsal and metatarsals of lower limbs (Table 3). Tarsals were involved in about two percent of our study population which correlates with others [9]. Sports injuries were not very common and only 2 percent of our patients presented with them. Though majority of the road traffic accidents involved tibia and femoral shaft fractures, inter-trochantric fractures were common in elderly females falling at home. Calcaneal fractures due to fall from height consisted of about 2 percent of the cases and metatarsal and phalyngeal fractures were about 4 percent of the reported patients (Table 3 ).

\section{Discussion}

In the city of Ahmedabad, just like any other developing city, there has been an increase in motor vehicular accidents due to rapid development of roadways and infrastructure. This has resulted in increased amount of trauma, especially to the lower limbs. As shown by Monk et al, lower limb injuries constitute the majority in trauma incidents [10]. Our study provides insight into the epidemiology of trauma in Ahmadabad. Little literature is available for such issues in India and a few international papers exist due to the difficulty obtained while performing them [11$14]$.

Males were affected thrice more often than females in this study (2.9:1). One of the reasons being that the road traffic accidents have been found to be the major contributor to isolated lower limb injuries. It is a general observation that road traffic accidents involve males more than females in the developing world. The demographic findings in this study resemble that of an urban area in western world with trauma patients being 
mainly males in their early forties or late thirties [15, 16]. A study recently revealed an $18 \%$ increased rate of injury amongst patients older than 65 years, which correlates with our findings [17].

Interestingly, at $72 \%$, our hospital sees a higher rate of road traffic accident related trauma, which is much higher than western world (33\% for United Kingdom [16] and $35 \%$ for United States [18]. Probable reasons for such an observation could be the close proximity of our hospital to the national highway and increased incidents of sports related injuries in the western world.

In recent times, just like any other developing nation, union and state ministry of Gujarat are spending heavily to create trauma and emergency structures in the cities of this state and at many places trauma centres have been established. At this point, such a study is inevitable. Studies like this have been conducted in cities like Delhi, Mumbai and Lucknow. They have helped dramatically in the development of effective trauma centres [10]. There is lack of accurate and uniform data in developing nations like India as trauma registry does not exist.

The current study gives detailed information on the distribution patterns of isolated lower limb injuries and their causes in Ahmedabad. This may provide insight to the ways to reduce lower limb injuries and enforce preventive measures in the population. The bimodal age pattern of lower limb injuries and varied distribution of fractures is also interesting. This may further encourage studies by preventive medicine, emergency physicians, orthopaedicians and trauma specialists.

In this age where trauma is not limited to a particular country and road traffic accidents are becoming the major cause of injuries. It has become indispensible to conduct such studies. This will not only help in developing preventive measures at the local level but also strengthen research internationally. This will also support the developing nations in imbibing qualities from developed world and reduce morbidities and mortalities due to trauma.

\section{Conclusion}

According to the mapping of the profile of individuals involving lower limb injury at the emergency department of at our hospital, it was possible to identify some characteristics that may be useful for planning prevention strategies such as the development of protection mechanisms for lower limbs, stimulating the enforcement regarding the compliance of traffic laws by drivers, awareness of safety measures in an attempt to reduce the numbers of accidents and redirect public investment in health.

In the current era of advanced technology ; it is not difficult to set up trauma registry. Such an initiative should be taken by the government to appropriately manage trauma victims. This will further reduce load on economy by avoiding morbidity and dependency.

Financial Disclosure: There are no relevant financial interests or financial conflicts within the last five years and for the foreseeable future. The authors have no financial interests related to the material in the manuscript.

Funding and Support: There has been no funding support for this study.

Acknowledgements: The authors would like to gratefully acknowledge the huge efforts made by the residents and staff at Vadilal Sarabhai General Hospital, Ahmedabad in the collection of the raw data.

\section{Conflict of Interest: None}

\section{References}

1. Sinha AK, Boot DA, Gorman DF, Teanby DN. Severe motorcycle injury in Mersey region and North Wales. Injury. 1995;26(8):543-545. doi: 10.1016/00201383(95)00078-N.

2. Wells S, Mullin B, Norton R, Langley J, Connor J, Lay-Yee R, Jackson R. Motorcycle rider conspicuity and crash related injury : case control study. BMJ. 2004 Apr 10;328(7444):857. Epub 2004 Jan 23.

3. Miki N, Martimbianco AL, Hira LT, Lahoz GL, Fernandes HJ, Dos Reis FB. Profile of trauma victims of motorcycle accidents treated at hospital Sao Paulo. Acta Ortop Bras. 2014;22(4):219-22. doi: 10.1590/1413-78522014220400642

4. Aare M, von Holst H. Injuries from motorcycle and moped crashes in Sweden from 1987 to 1999. Inj Control Saf Promot. 2003 Sep;10(3):131-8.

5. Ankarath S, Giannoudis PV, Barlow I, Bellamy MC, Matthews SJ, Smith RM. Injury patterns associated with mortality following motorcycle crashes. Injury. 2002 Jul;33(6):473-7. 
6. Babak Haghpanah. Transforming phase of Fracture Epidemiology. Archives of Trauma Research. 3(3): e23364, DOI: 10.5812/atr.23364

7. Tham KY, Seow E, Lau G.. Pattern of injuries in helmeted motorcyclists in Singapore. Emerg Med J. 2004 Jul;21(4):478-82.

8. Russell WL, Sailors DM, Whittle TB, Fisher DF Jr, Burns RP. Limb salvage versus traumatic amputation. A decision based on a seven-part predictive index. Ann Surg. 1991 May;213(5):473-80; discussion 480-1.

9. Lil NA, Patel NB, Bhavsar NM, Adatia AA, Patel PR .Outcome of Calcaneal Plating after fracture : two year follow up. Int J Med Res Rev 2014; 2(2):102-109

10. Monk JP, Buckley R, Dyer D. Motorcycle-related trauma in Alberta: a sad and expensive story. Can J Surg. 2009 Dec;52(6):E235-40.

11. Kumar S, Chaudhary S, Kumar A, Agarwal AK, Misra MC. Trauma care- a participant observer study of trauma centres at Delhi, Lucknow and Mumbai. Indian J Surg. 2009 Jun;71(3):133-41. doi: 10.1007/s12262-009-0037-0. Epub 2009 Jun 10.

12. Orsay E, Holden JA, Williams J, Lumpkin JR. Motorcycle trauma in the state of Illinois: Analysis of the Illinois department of public health trauma registry. Ann Emerg Med. 1995 Oct;26(4):455-60.
13. Santos AM, Moura ME, Nunes BM, Leal CF, Teles JB. Profile of motorcycle accident victims treated at a public hospital emergency department. Cad Saude Publica. 2008 Aug;24(8):1927-38.

14. Koizumi MS. Injury patterns in motorcycle accident victims. Rev Saude Publica. 1992 Oct;26(5):306-1

15. Wui LW, Shaun GE, Ramalingam G, Wai KM. Epidemiology of trauma in an acute care hospital in Singapore. J Emerg Trauma Shock. 2014 Jul;7(3):1749. doi: 10.4103/0974-2700.136860.

16. DGU Annual report [Internet]. Available from: http://www.traumaregister.de/images/stories/dow nloads/englisch/TR-

DGU_annual_report_2013.pdf

17. Christensen MC, Ridley S, Lecky FE, Munro $\mathrm{V}$, Morris S. Outcomes and costs of blunt trauma in England and Wales. Crit Care. 2008;12(1):R23. doi: 10.1186/cc6797. Epub 2008 Feb 19.

18. Ciesla DJ, Pracht EE, Tepas JJ 3rd, Cha JY, Langland-Orban B, Flint LM.The injured elderly: a rising tide. Surgery. 2013 Aug;154(2):291-8. doi: 10.1016/j.surg.2013.04.025

19. NTDB Annual Report 2012 [Internet]. Available from:

http://www.facs.org/trauma/ntdb/ntdbannualreport2010. pdf

\section{How to cite this article?}

Goel SA, Bhavsar NM, Makwana H, Lil NA, Patel PR. Epidemiology and patterns of lower limb injuries at a tertiary care hospital in Ahmedabad. Int J Med Res Rev 2015;3(5):490-496. doi: 10.17511/ijmrr.2015.i5.094. 